\title{
Pharmacological In vivo Test to Evaluate the Antidepressant Activity of Polyherbal Formulation
}

\author{
Rinki Kumari ${ }^{1}$, K. Ilango ${ }^{2}$, G.P.I. Singh ${ }^{3}$, G.P. Dubey ${ }^{1 *}$
}

${ }^{1}$ Institute of Medical Sciences, Banaras Hindu University, Varanasi- 221005

2Interdisciplinary School of Indian System of Medicine, SRM University, Katankulathur, Chennai

${ }^{3}$ Adesh University, Barnala Road, Bathinda, Punjab

\begin{abstract}
The antidepressant effects of the polyherbal formulation (PF) (contain four extracts of medicinal plants namely: Nyctanthes arbortristis, Hippophae salcifolia, Ocimum tenuiflorum and Withania somnifera ) was examined by evaluating the extent of reduction of behavioural alterations and neurotransmitter in the rats stressed by forced swim test (FST). In the present study, compared with the model control group (FST), the altered behavioural parameters were attenuated significantly $(\mathrm{P}<0.05)$ in the group treated with the PF $(100,200$ and $400 \mathrm{mg} \mathrm{kg}-1)$, comparable with the standard drug treated group, Sertraline $(10 \mathrm{mg} \mathrm{kg}-1)$. The PF and Sertraline significantly $(\mathrm{P}<0.05)$ increased the level of the neurotransmitter such as serotonin, dopamine, acetylcholine and noradrenalin whereas decreased the level of monoamine oxidase along with oxidant in the brain of the stressed rats. PF and Sertraline were also involved in the reduced oxidant and generated antioxidant in the stressed rats. The results indicated that polyherbal formulation exhibited significant antidepressant activity, as indicated by its ability to decrease force swim stress, induced immobility time in rats as well as restoring the biogenic amines to normal level that were altered by the swim induced stress in whole rat brain. Therefore, PF can be a potential candidate for treatment of depression as well as a potent antidepressant. However, further studies are required to substantiate the same.
\end{abstract}

Keywords: Depression, Antidepressant, Nyctanthes arbortristis, Hippophae salcifolia, Ocimum tenuiflorum, Withania somnifera, Forced swim test.

*Corresponding author

E-mail: gpdubey13@gmail.com

\section{Introduction}

Depression is an etiologically heterogeneous group of chronic psychiatric illness with a high prevalence rate $(21 \%)$ and the second leading cause of the loss of human disability-adjusted life year [1-4]. The prevalence rate of depression is $6-8 \%$ in female and $3-5 \%$ in male [5]. Clinically characterized by a wide range of symptoms that reflect alternation in cognitive, psychomotor, biological, motivational, behavioral, emotional process and refers to either negative effect or absence of positive effects. The studies have suggested, depression also affects the quality of life of many people and has become a major cause of suicidal death [6-9].

Although, treatment of depression entirely depends on clinically available synthetic antidepressants (that based on serendipitous, act via monoamine neurotransmitters, such as serotonin and noradrenaline). Only certain portion of the patients show full remission in response to these antidepressants and other hand, associated with more side-effects and the chronic toxicity that affect almost every organ system. These available drugs have potential for adverse effects on cognition and behavior [1011]. To obtain better therapeutic benefits and minor adverse reactions, there is a pressing need for alternative antidepressant from natural source i.e., herbal remedies, used traditionally, now documented with safe profile [12-13]. Recently, it has been reported the use of polyherbal formulation exhibiting synergistic activity achieving maximum beneficial potency as compared to single herb [14-15].

The use of PF finds the way of curing depression. Ayurveda declared, more than a 
few plants of this formulation, the so-called "medhya" plants, possess such antioxidant, antidepressant and anxiolytic properties. Nyctanthe sarbor-tristis, (N. arbor-tristis,) (Family Oleaceae) is an herb that has been used in India for centuries as an anti-inflammatory [16], analgesic, antipyretic, ulcerogenic activities [1720], immunostimulant activity and anxiolytic activity. Hippophae salcifolia (H. salcifolia) (Seabuckthorn) are deciduous shrubs in the family Elaeagnaceae that traditionally used as anti-stress and improve, enhance physical endurance, mental function alone but there are limited published data in related to centrals nervous system disorders [19-21]. It has also shown anti-oxidant, immuno-modulatory, antiinflammatory and homocysteine lowering effects because it is a rich source of flavonoids, vitamins, proteins, amino acids, folic acid, phytosterol, alpha-tocopherol and phenolic compounds [21].

Ocimum tenuiflorum (O.tenuiflorum) (Family Lamiaceae), has wild growth and available throughout the Eastern World Tropics and contains eugenol, oleanolic acid, ursolic acid, rosmarinic acid, etc. It has a vast number of therapeutic applications such as cardiopathy, haemopathy, leucoderma, asthma, bronchitis, catarrhal fever, otalgia, hepatopathy, vomiting, lumbago, hiccups, ophthalmia, gastropathy, genitourinary disorders, ringworm, verminosis and skin diseases etc due to presence of abundance of naturally occurring polyphenols in Ayurveda, Greek, Roman, Siddha and Unani. These polyphenols possess potential effects of neuroprotection. Due to high concentration of eugenol act as COX-2 inhibitor and analgesic effect [22-28].

Withania somnifera (W. somnifera) is known as Ashwagandha, an Ayurvedic formulation mentioned in traditional medicine system, used as a mild sedative, aphrodisiac rejuvenative and possess a very good effect in all psychological disorders. The roots of $W$. somnifera consist very active compounds known as withanolides, is a strong potent psycho neuro pharmacologically active molecules and is subjected for antidepressant activity. Various studies have shown it is effective in the treatment of chronic fatigue, nervous exhaustion, and memory loss and neurodegenerative disorders and there are limited published data [29-30]. Even though PF has antidepressant potential, there is no sufficient evidence for its effects in animal models of depression. According to Ayurveda"Sarangdhar Samhita" dated centuries ago in $1300 \mathrm{AD}$ has highlighted the concept of polyherbalism in this ancient medicinal system to achieve additional therapeutic effectiveness [31].

Recent studies have shown that different herbal active bio molecules of $\mathrm{PF}$, possess potential effects of neuroprotection [32-35]. So far, no study has appeared about the protective effects of this polyherbal formulation on depression induced by forced swim stress. Considering substantial neuroprotective properties of $P F$, we sought to investigate whether $P F$ could improve level of neurotransmitter induced by Forced swim stress in rats; and to explore the underlying mechanisms for the same.

\section{Materials and Methods Animals}

Albino Wistar rats (with 2 months of age and both genders), weighing 150 to $200 \mathrm{~g}$ were taken from the central animal house of Adesh University, Bathinda, Punjab. All animals were kept in polypropylene cages with paddy husk as bedding. The rats were housed in groups of 6 animals per cage and acclimatized to a colony room with a controlled ambient temperature 23 $\pm 2^{\circ} \mathrm{C}$, relative humidity of $50-70 \%$ and a 12 hour natural light/dark cycle. The animals had free access to pelleted feed of standard composition containing all macro and micro nutrients and purified water ad libitum and were acclimated for 7 days prior to the consequent studies. The animals were examined at regular intervals by a trained personal for any behavioural abnormalities and behavioural studies were carried out during the light phase (10.00 am-1.00 pm). The animals were used only once for each experiment. The experiments were performed after approval of the protocol by the Ethics Committee of the Adesh University, Bathinda Punjab with reference number; 
AIMSR/MC/Estt/07/2009/718 \& dated 16-072009.

\section{Collection of polyherbal hydro- alcoholic extract}

The hydro-alcoholic extracts of four plantsNyctanthe sarbortristis (75mg), Occimum tenniflorum (50mg), Hippophe salcifolia (40mg) and Withania somnifera (35mg) in the combination as a polyherbal formulation (PF). The source of hydro-alcoholic extract of four plants from Bajinath Pharmaceutical Pvt. Ltd., Paprola Himachal Pradesh. PF was freshly suspended in distilled water and administered per oral (p.o.) in a constant volume of $10 \mathrm{ml} / \mathrm{kg}$. The dose of extracts per rat was calculated with the values obtained in gravimetric assay and estimated at $2000 \mathrm{~g} / \mathrm{kg} /$ day. Different doses of test drug $(100,200,400 \mathrm{mg} / \mathrm{kg} /$ day $)$ were administered orally by using oral gavage in rats, 40-45 min before the behavioural tests. Sertraline HCL was used as the reference standard drug for evaluating antidepressant activity. Sertraline HCL suspension was prepared using saline.

\section{Drug and analytical chemical}

Sertraline hydrochloride, (1S,4S)-4-(3,4dichlorophenyl)-N-methyl-1,2,3,4-tetrahydronaphthalen-1-amine selective reuptake inhibitor antidepressant, was gifted from Sun pharmaceutical company Baddi, Himachal Pradesh and used as positive control for antidepressant action. All other reagents and solvents were of analytical grade. Polyherbal formulation was dissolved in $0.5 \%$ Carboxyl Methyl Cellulose (CMC) with 1\% Tween 80 (solubility enhancer). The dissolution of the extract wasfreshly done from the powder immediately before its administration. A control group received equal volume of distilled water.

\section{Experimental design}

There were six groups in this present study: Group I: 0.5\% Carboxyl Methyl cellulose (CMC) plus unstressed, Group II: Water plus Stressed, Groups III: Sertraline hydrochloride (10 $\mathrm{mg} \mathrm{kg}-1$, i.p.) plus stressed and the at $30 \mathrm{~min}$ before exposure to stress), Group VI and IV: PF (polyherbal formulation) plus stressed (100, 200 and $400 \mathrm{mg} \mathrm{kg}^{-1}$ p.o., respectively) (treatment at $60 \mathrm{~min}$ before exposure to stress). PF and sertraline hydrochloride were each given orally by gavage, $60 \mathrm{~min}$ before each stressor once every day for $7^{\text {th }}, 14^{\text {th }}$ and 28 days.

\section{Measurement of immobility period by forced swim test (FST)}

The forced swim test was performed according to the method described by Porsolt [36] with slight modifications [37].This test consisted of two parts, an initial training period of $15 \mathrm{~min}$ and an actual test for $5 \mathrm{~min}$ after $24 \mathrm{~h}$. The rats were individually forced to swim inside vertical plastic jar $(26 \mathrm{~cm} \times 12 \mathrm{~cm} \times 26 \mathrm{~cm})$ containing water to a height of $15 \mathrm{~cm}$ at $25 \pm 2{ }^{\circ} \mathrm{C}$ for a $5 \mathrm{~min}$ session every day for 7 days. When they were placed in the glass jar for the first time the rats were initially highly active, vigorously swimming in circles, and trying to climb the wall or diving to the bottom. After 3-4 min, their activity began to fall down and immobility increased. After 5-6 min, immobility reached a raised ground where the rat remained immobile more than $70 \%$ of the time. After $15 \mathrm{~min}$ in the water, the rats were removed, wiped with dry cloth and allowed to dry before being returned to their cages. The plastic jar was emptied and washed thoroughly after testing for each rat. The rats were again placed in the jar $24 \mathrm{~h}$ later after initial administration of the drug and extracts and their activity was recorded within 5 min. The duration of immobility was measured using a stop watch. An animal was judged to be immobile whenever it remained floating passively in the water in a slightly hooked but vertical position and sometime horizontal position, with no additional activity other than that necessary to keep its head above water [3637].

\section{Behavioral assessment}

Numerous other behavioral parameters were assessed in the rats on 7th, 14th and 28th days after forced swim stress test. All the animals were subjected for other behavioral analysis such as anxiety and memory. The mirror chamber test was used as a measure of anxiety [38] while for cognitive behavior the elevated 
plus maze test was used, developed by Kulkarni [39].

\section{Biochemical assay}

\section{Biochemical tests for neurotrans- mitter and other biomarker in all rats}

On Day $7^{\text {th }}, 14^{\text {th }}$ and $28^{\text {th }}$, after mentioned behavioral analyses, the rats were immediately sacrificed by cervical dislocation. The brains were immediately removed and $10 \%(\mathrm{~W} / \mathrm{V})$ tissue homogenate was prepared in $0.1 \mathrm{~mol} \cdot \mathrm{L}-1$ phosphate buffer ( $\mathrm{pH}$ 7.4). The homogenates were centrifuged for 15-20 min at $10000 \mathrm{~g}$ and the supernatants were used for analyses of serotonin, melatonin, monoamine oxidase, noradrenalin, acetylcholine, lipid peroxidation and glutathione levels. The serotonin and melatonin were estimated according to the methods described by Snyder et al [40] and Ozaki et al [41] respectively in the brain tissue. The level of monoamine oxidase in the rat brain tissue was measured by using the procedure of $\mathrm{Xu}$ et al. [42] with a minor modification and noradrenalin and acetylcholine, estimated by high performance liquid chromatography with fluorescence detection (HPLTC) method [28].Lipid peroxidation was assayed byof the presence malondialdehyde, a biomarker in form of thiobarbituric acid-reactive substances by the method of Wills et al [43] whereas glutathione in brain was analyzed according to the method described by Ellman et al [44].

\section{Data analysis}

Behavior assay was analyzed statistically using Graph pad prism a one-way analysis of variance (ANOVA), followed by Turkey's test. The results were expressed as the mean \pm standard error of the mean (SEM.). Differences with $p$ values $<0.05$ were considered statistically significant. For biochemical assays, one-way ANOVA was applied on the percentage values of each group calculated with respect to positive and negative control group. The values were expressed as mean \pm SEM.

\section{Results}

Body weights on 7 th, 14th, and 28th days

At the beginning of the experiment, there were no significant differences in body weight among the six groups $(\mathrm{P}>0.05)$, with the values (mean \pm SD) being $104 \pm 2.45,101.71 \pm 6.2,103.52 \pm 1.15$, $105.59 \pm 12.45,107.98 \pm 15.6,104.9 \pm 7.78$ and for groups 1-6 respectively. The body weights at the 7th, 14th and 28th days of the treatments were also not significantly different among the groups ( $\mathrm{P}>0.05)$; the values of 7 th days were $106 \pm 3.2,105.51 \pm 7.45,104.92 \pm 2.15,108.47 \pm$ $13.1,109.91 \pm 6.12,105.9 \pm 5.78$ and 14 days were $133.3 \pm 15.57,129.35 \pm 28.62,123.95 \pm 15.43,131.09$ $\pm 28.78,135.64 \pm 24.16$ and $125 \pm 31.22$ whereas on the 28days the value of body weight were 135.80 $\pm 12.6,131.33 \pm 17.98,133.19 \pm 12.2,135.9 \pm 13.04$, $139.19 \pm 44$, and $133.33 \pm 5.2,1-6$ respectively. Therefore, the results suggested that polyherbal formulation or Sertraline didn't show any toxicity effect in treatment group.

\section{Effects of polyherbal formulation (PF)} on the immobility time in the forced swim (FST) test and its anti-anxiety-

After treatment with the PF for 7,14 and 28 consecutive days, there was a significant reduction in immobility time in the forced swim test, in a dose-dependent manner, compared with the experimental control (stressed) rats ( $\mathrm{P}$ $<0.05$, Figure 1). The reduction in immobility after the treatment with the PF demonstrated its antidepressant-like potentials, since decreased swimming performance would increase the immobility time in the forced swim test. Sertraline was used as the standard drug for antidepressant activity on the forced swim test. As presented in Figure 1, Sertraline caused a significant reduction in immobility time. Effect of test drug on biochemical parameters.

PF were also exerted anti-anxiety like effect because it decreased time latency to enter in mirror chamber and also increased number of entries in stressed rat. Figure $2 \mathrm{a}$ to $\mathrm{c}$ showed the standard drug, Sertraline, was more effective than the PF $(\mathrm{P}<0.05$, Figure. $2 \mathbf{a}, \mathbf{b}$ and $\mathbf{c})$. 


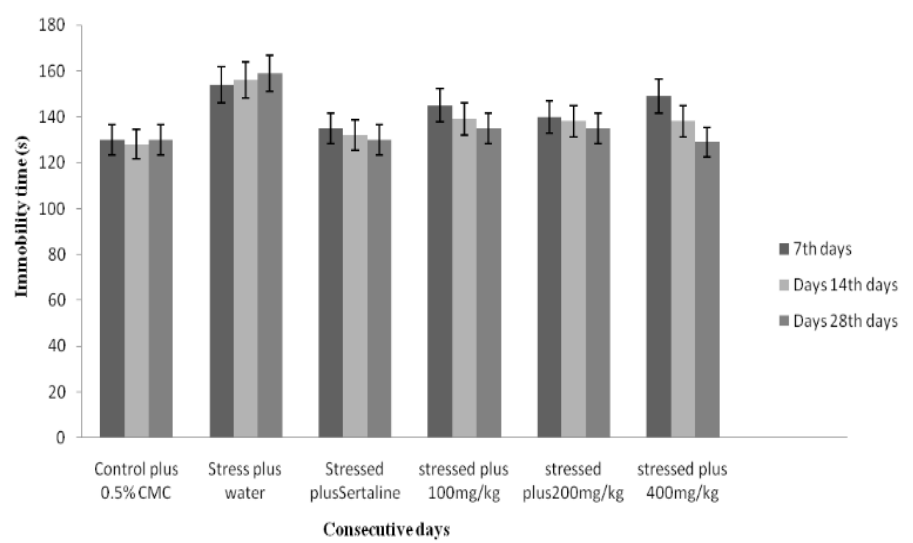

Figure. 1: Effect of PF on the immobility time in the stressed rats. Sertraline was used as a positive control.

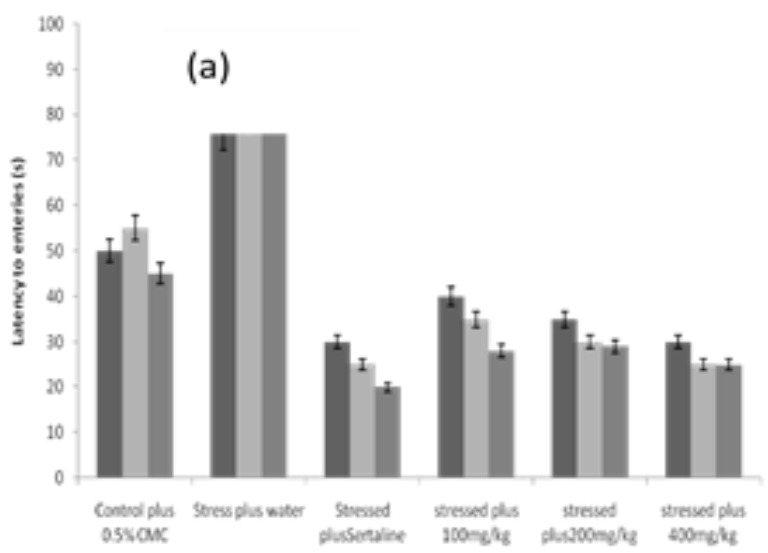

Ithden

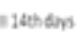

nashow

(b)
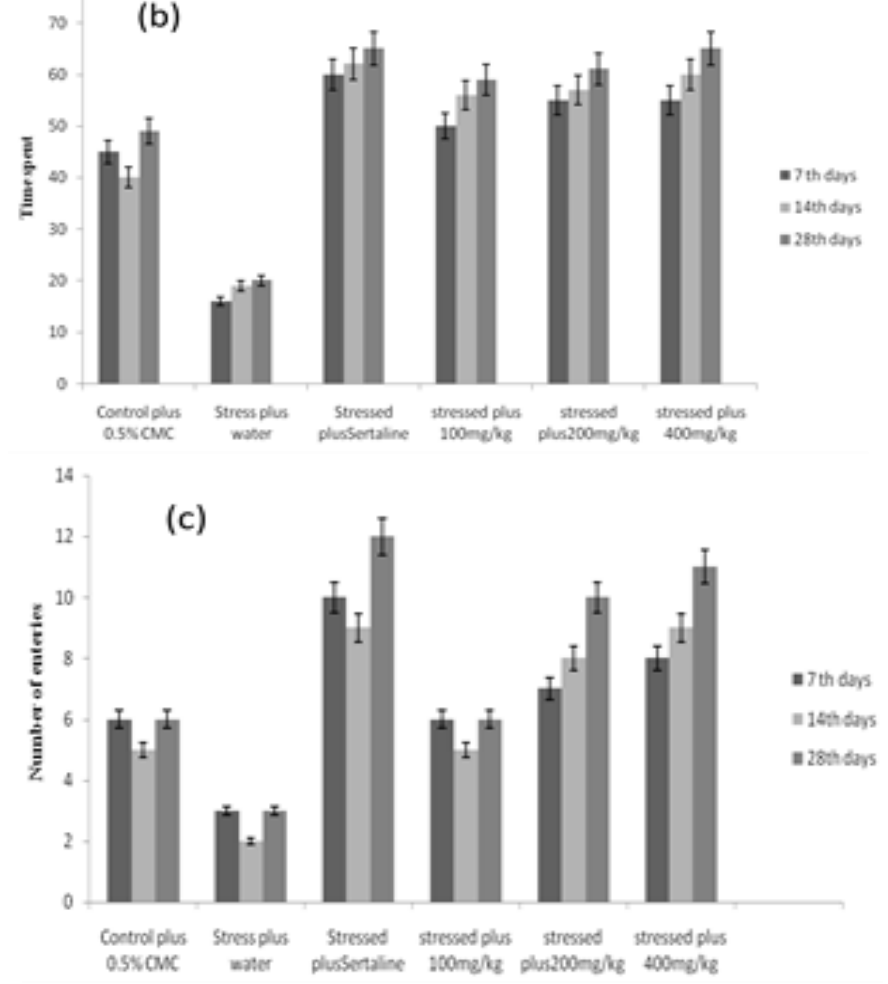

Figure.2: Effect of the PF on Anxiety (a) latency of entries (s) (b) Time spent and (c) Number of entries
Effect of polyherbal formulation (PF) treatment on biochemical parameter: Brain serotonin levels

Serotonin levels were estimated in the whole brain content of rats. FST model exhibited significantly lower value of serotonin levels, expressed as percentage values with respect to the control group. More than a $40 \%$ decrease in serotonin levels was observed due to depression induced model group. PF treatments showed significantly increased brain serotonin levels in model group (Figure 3). Also, Sertraline was increased the level of serotoninin the brain of stressed rats as compared to model group.

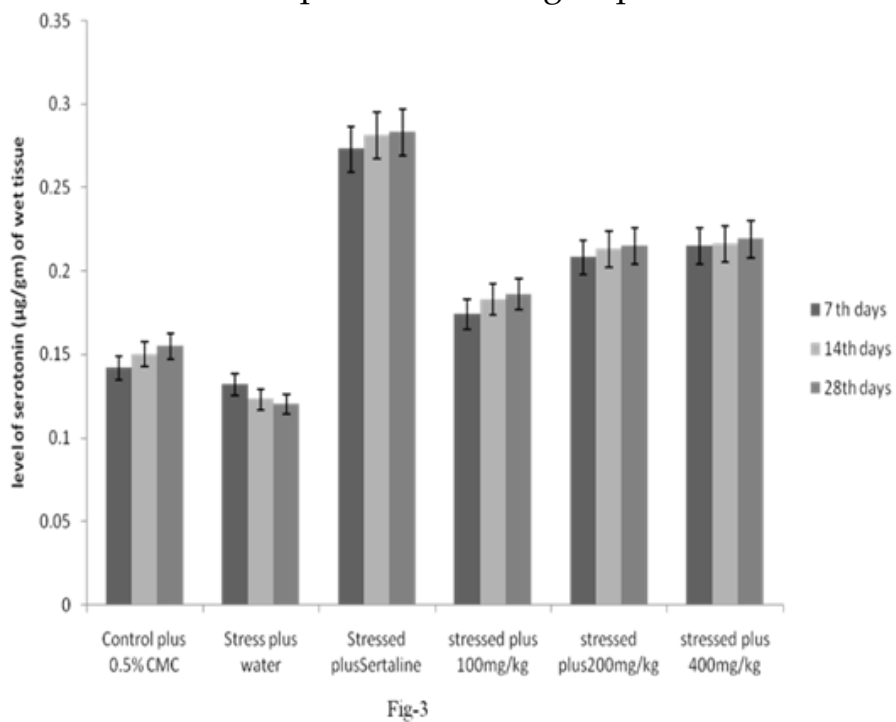

Figure. 3: Effect of the PF on level of serotonin in stressed rat's brain

\section{MAO enzyme activity}

FST model rats resulted in a significant increase in total MAO enzymatic activity in the brain as compared to the Sertraline and test drug treatment group. The effects of PF and Sertraline on the MAO activities in the rat brain are shown in fig 4. Test drug at doses of 100, 200 and 400 $\mathrm{mg} / \mathrm{kg}$ suppressed the brain monoamine oxidase activities. The data represented 25. $2 \%$ increases in total MAO activities in the whole brain content of FST rats with respect to Sertraline treated rats respectively. PF treatment significantly reduced the level of total MAO enzyme activities in the brain within 28 days at $400 \mathrm{mg} / \mathrm{kg}$. Similar results were observed for the Sertraline treatment. 


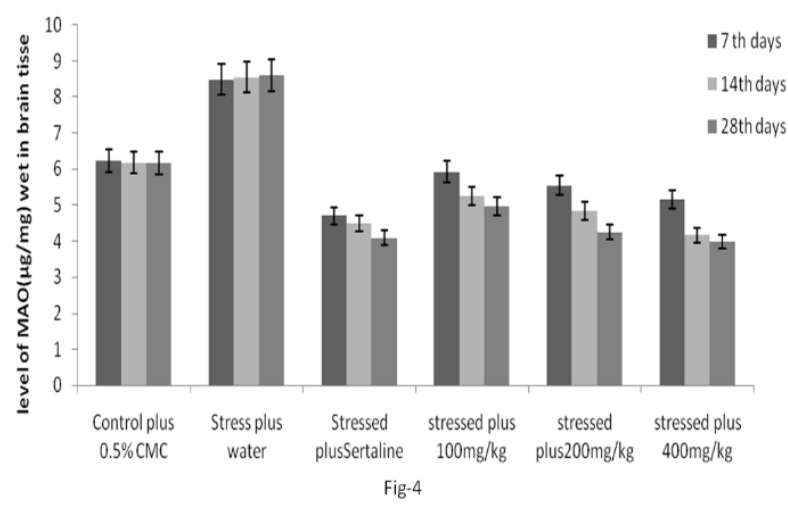

Figure. 4: Effect of the PF on level of MAO in stressed rat's brain

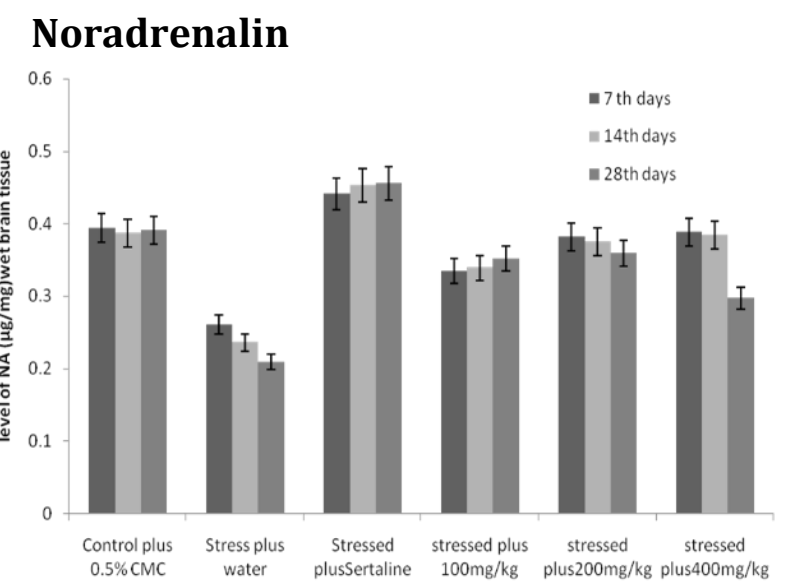

Figure. 5: Effect of the PF on level of noradernalin in stressed rat's brain

Noradrenalin levels were estimated in the whole brain content of rats. Model group exhibited significantly lower value of noradrenalin levels compared to the control group. PF treatments showed significantly increased brain noradrenalin levels in treated group (Figure 6).

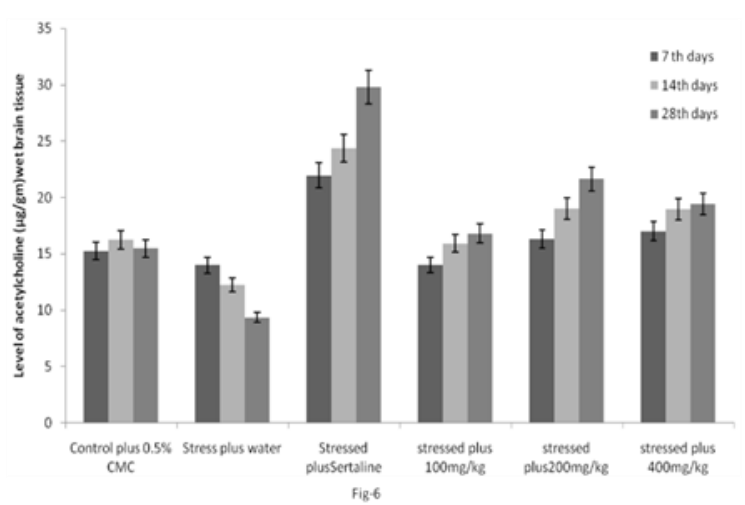

Figure. 6: Effect of the PF on level of acetylcholine in stressed rat's brain

Also, Sertraline showed recovered brain noradrenalin levels increase as compared to model group. At the dose, $400 \mathrm{mg} / \mathrm{kg}$ significantly increased the level of noradrenalin in the brain of depressive rats and this concentration is effective doses for recovery of noradrenalin in the brain.

\section{Acetylcholine}

PF gradually increased the level of acetylcholine in the brain of depressive rats while $200 \mathrm{mg} / \mathrm{kg}$ concentration significantly increased level of acetylcholine. These level are lower as compared to standard drug figure 6.

\section{Lipid peroxidation and glutathione}

PF gradually increased the level of malondialdehyde in the brain of depressive rats while these level are lower as compared to standard drug figure 7. Simultaneously; we observed the glutathione level in brain of stressed rats decreases.

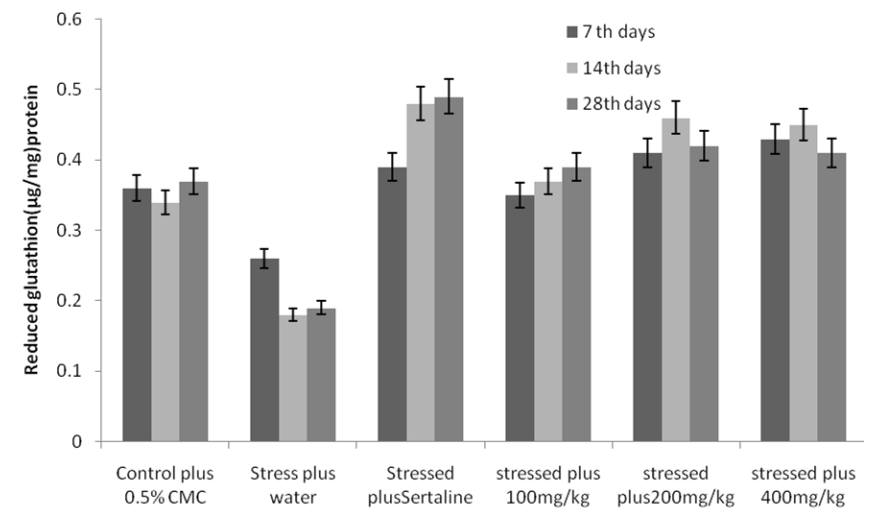

Figure. 7: Effect of the PF on level of reduced glutathione in stressed rat's brain

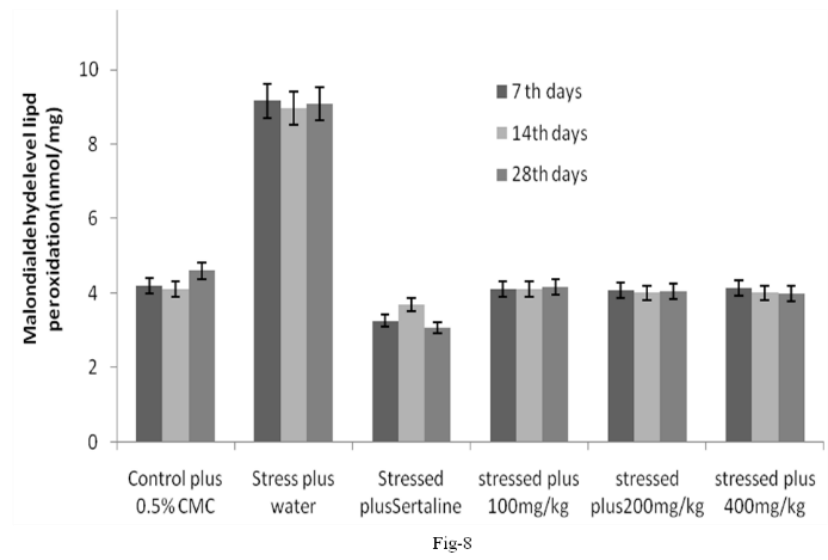

Figure. 8: Effect of the PF on level of lipid peroxidation biomarker in stressed rat's brain

\section{Discussion}

After screening of plants having role on central nervous system four plants namely Nyctanthes 
arbortristis (parijata), Hippophae salicifolia (amlavetas), Occimum tennuiflorum (van tulsi) and Withania somnifera were selected on the basis of their biological activity. Hydro-alcohol extract of four medicinal plants(Nyctanthe sarbortristis; Hippophae salcifolia ;Ocimum tenuiflorum ; Withania somnifera) has been reported to possess potent different activityanti-inflammatory, anti-oxidant,COX-2 inhibitor and analgesic effect and chronic fatigue, nervous exhaustion, memory loss, neurodegenerative disorders etc, respectively due to presence of major effective constituents such as nyctanthic, lupeol, ascorbic acid, flavonoids, folic acid, oleanolic acid, ursolic acid, rosmarinic eugenol and 35 withanolides with 12 alkaloids and several sitoindosides [1630]. Therefore, all the four plants have shown their action on various targets involved with depression like monoamine content, proinflammatory markers, behavioral pattern etc and the selected four plants were taken and after determination of bio-activity the plants were taken for standardization and quality control studies and to develop a polyherbal formulation beneficial in the management of depression of varying etiology. We hypothesized PF could be effective in the management of diseases caused by imbalance of monoamines or neurotransmitter, inflammatory, injury fatigue and oxidative stress. To test the hypothesis, we evaluated the effects of the nyctanthic, oleanolic, eugenol, withanolides, flavonoids and folic acid rich hydro-alcoholic extract on behavioral alterations in stressed rats.

The present study can be summarized by following finding: 1 . the force swim stress procedure caused depressive-like behavior in treatment rats, as observed by different assays such as mirror chamber test and elevated plus maze test; 2 . significant reduction in depressivelike behaviors was evident in the stressed rats treated with PF and Sertraline (positive control); 3. forced swim test procedures imbalance the neurotransmitter and induced inflammatory injury along with oxidative damage by increasing lipid peroxidation in the treated rats and 4. PF and Sertraline treatments exerted protective effects against forced swim stress and increase the level of neurotransmitter and decrease the glutathione in the rat brain.

Numerous studies have been indicated that stressful life events and chronic stresses are risk factors for several neurodegenerative diseases including depression because it is capable to altering physiological homeostasis of body and imbalance the neurotransmitter in brain [45-47]. Depression is an incapacitating psychiatric ailment which is characterized by a pervasive low mood, loss of interest in usual activities, diminished ability to experience pleasure (anhedonia), withdrawal of interest, feelings of worthlessness, and suicidal tendencies [1-9].

Most commonly, FST is employed behavioral model of depression and used to evaluate the antidepressants drug [48]. The poly herbal formulation as found to be safe in as no mortality was observed following treatment. The immobility exhibited by test animals in these models is an indicative of a behavioral despairness which reflects a state depressive state. Group IV to VI showed a significant decrease in their immobility time showed a moderately significant decrease in immobility time compared to control and model group. Sertraline showed extremely significant reduction in the immobility time.

On the other hand, anxiety is a part of which is psychological and behavioral state induced in animals and humans by stress-like conditions and characterized by fear and annoyance. Serotonin level is decreases in the anxiety condition [38]. In our present study, anxiety evaluated by mirror chamber test [39] and we found the PF and Sertraline both significantly increase the time spent, number of entries and decreases latency entries (Figure 2)and increase the serotonin in the stressed rats.

The elevated plus maze test is used to evaluate cognitive behavior and memory performance [49]. According to the report $[49,50]$, the rodents are like to live in enclosed and dark area. Our data of this behavior assays showed that PF, changes in both open arm entries and time spent in open arms significantly $(\mathrm{P}<0.05)$ and Sertraline is also increased the open arm entries and time spent in open arm $(\mathrm{P}<0.05)$ whereas model group showed significant reduction in 
open arm entries and the time spent in open arm $(\mathrm{P}<0.05)$. Therefore, this study showed that PF and Sertraline, both promote glucocorticoid production and release in the adrenal cortex [50].

As we know Sertraline acts by the selective serotonin reuptake inhibitor (SSRI) pathway and has been used as a standard drug in majority studies. The beneficial effect of Sertraline in the FST model seems to be due to increased availability of these neurotransmitters nor epinephrine (NE), acetylcholine, melatonin and serotonin (5HT) at the post synaptic site following reuptake inhibition due presence of potential phytocontituents and so forth produces anti-depressive actions. On the other hand, depression is a multifaceted mental illness resulting from alterations in central serotonergic, melatonin, noradrenergic, and system along with MAO activity. The monoaminergic hypothesis of depression postulates that the major neurochemicals process in depression, is the impairment of monoaminergic neurotransmission and the concomitant decrease in extracellular concentration of noradrenaline and serotonin $[36,44,51]$. Most of the prescribed antidepressants inhibit serotonin or noradrenaline reuptake and mono amineoxidase inhibitors act by increasing the synaptic availability of these neurotransmitters $[36,44]$. The dopaminergic system is also an important target implicated in the regulation of mood disorders, as preclinical and clinical studies have indicated a diminished dopamine turnover in depression [36]. As a result, depressive disorders are commonly due to imbalance in neurotransmission and it bring this imbalance back to balance consists in inhibiting the uptake of neurotransmitters into the neurons, thus neurotransmitters levels increasing in the brain and shown to improve the clinical symptoms of depression. Among them are chemical entities like tricyclic antidepressants or herbal extracts as demonstrated here and by many others [34-38]. Consequently, it was thought to be worthwhile to estimate all the five neurotransmitters in brain of rats depressed by forced swimming and tail suspension test. Model group have shown decreased levels of 5-HT, melatonin, NA, and acetylcholine with increases the activity of $\mathrm{MAO}$, indicating a state of depression while treated animals exhibited increased levels of these biogenic amines and low level of MAO activity. In that test drug $400 \mathrm{mg} / \mathrm{kg}$ produced a significant increase in 5-HT, melatonin, NA, and acetylcholine levels at 28 th days. This effect was comparable to the standards used.

Various studied have been shown the oxidative stress has been associated in the pathophysiology of many neurological disorders and caused anxiety and stress lead to depression [52-53] due to reactive oxidative stress (ROS) as like hydroxyl radicals, superoxide anion, hydrogen peroxide and nitric oxide. These are involved in the oxidative damage to lipids, neuronal inflammation and reduced intracellular antioxidant altered the membrane function and signaling process in the brain [54-55].

In the present study, forced swim test caused the stress, lead to oxidative damage in stressed rats and decreases the glutathione, represents a main cellular non-protein and antioxidant that redox regulator in protecting oxygen species. It also regulate lipid peroxidation and also decrease in catalase activity. Studies had been reported that catalase and lipid peroxidation, are lined to depressant-like behavior. In the present studies we found that malondialdehyde (biomarker of lipid peroxidation) is higher in the FST model whereas its level was reduced in PF and Sertraline treated rats because the both drugs induced the more synthesis of reduced glutathione, involved in diminished catalase activity [56-57]. Studies have been shown these catalase activity increases lipid peroxidation through metals transition reaction resulting generate the radical hydroxyl, which cause oxidative injury, inflammation and neuronal damage. Therefore, PF and standard drug increased the level of glutathione in the stressed rats and protecting the neuron from oxidative stress and damage. As a result, all of these plants are classified in Ayurveda as rasayanas which are apparent to promote mental health, improve 
immunity and enhance long life of individuals [58-59].

Further studies will reveal the mechanisms by which test drug synergistically enhances the antidepressant activity especially on the serotonergic system. Taken together, our data proved that the anti-depressive therapeutic effects of test drug are possible with $400 \mathrm{mg} / \mathrm{kg}$ doses, when it compared with standard. This might be due to different mechanisms by which four extracts act on the neurotransmitter system.

\section{Conclusion}

In the present study, forced swim stress (FST) was used to developed depressive like behavior in rats for 7, 14 and 28 days. It was an increased immobility time, anxiety and impaired cognitive behavior in the experiment rats (stressed). It was also imbalanced biochemical in FST model (stressed rats) through the reduction of different neurotransmitter that altered behavioral parameters and it were attenuated significantly by administration of the polyherbal formulation (PF) comparable to Sertraline. Both drugs were capable to reduce the oxidative stress and decreases the level of reactive oxidative species through increased the level of antioxidant in the brain. It was protected the neuron from the neuronal damage and improved the cognitive behavior. However, PF, centrally exerts an antidepressant-like effect in the FST by a mechanism involving inhibition of serotonin reuptake, inhibition of MAO activity and evaluated the level of acetylcholine, melatonin and noradrenaline in the brain. Given that these targets have been increasingly reported to be involved in the pathophysiology of depression and on the antidepressant efficacy. Thus, poly herbal extract possesses antidepressant action demonstrated by modulation of serotonergic pathway, MAO receptors, acetylcholine, noradrenalin and melatonin in rats.

\section{Declarations Conflict interests}

The authors declare that they have no conflict interests.

\section{Acknowledgments}

The authors would like to thank the Adesh University Punjab for their assistance and support. The authors wish to express their gratitude to Dr Arvind Shah, DrAnand Shah and all staff member of our laboratory.

\section{References}

1. Nemeroff $C B$, Owens MJ:Treatment of mood disorders. Nature Neurosci. 2002 5:1068-1070.

2. Shreevathsa M, Ravishankar B, Dwivedi R: Antidepressant activity of Mamsyadi Kwatha: An Ayurvedic compound formulation. Ayu. 2013 34(1): 113-117.

3. Belmaker RH, Agam G.: Major depressive disorder. N Engl J Med. 2008 1:55-68.

4. Katon W, Sullivan MD: Depression and chronic medical illness. J Clin Psychiat. 1990 51:12-4.

5. Reynolds EH: Brain and mind: a challenge for WHO. Lancet. 2003 361: 1924-1925.

6. AanHetRot M, Mathew SJ, Charney DS: Neurobiological mechanisms in major depressive disorder. CMAJ. 2009 180: 305-313

7. Bierut LJ, Heath AC, Bucholz KK, Dinwiddie $\mathrm{SH}$, Madden PAF, Statham DJ: Major depressive disorder in a community-based twin sample. Are there different genetic and environmental contributionsfor men and women? Arch Gen Psychiatry. 1999 56:557-563.

8. World Health Organization. WHO DirectorGeneral unveils new global strategies for mental health. 1999 WHO/9967.http://www.who.int/inf-pr1999/en/pr9967 .html.[Last accessed on 2012 Oct 12]

9. Brody TM, Frazer A, MorilakD: Drugs for the treatment of affective (mood) disorders. In, Larner J, Minneman KP, eds. Human pharmacology: molecular to clinical, third ed. St. Louis: Mosby 1998 349-363.

10. Brunello N, Mendlewicz J, Kasper S, Leonard B, Montgomery S, Nelson JC, et al: The role of noradrenaline and selective noradrenaline reuptake inhibition in depression. Eur Neuropsychopharmacol. 2002 12,:461-75.

11. Thasa ME, Entsuah AR, Rudolph RL: Remission rates during treatment with venlafaxine or selective serotonin reuptake inhibitors. Br J Psychiatry. 2001 178:234-41.

12. Kumar B, Jindal A, Pandey DK, Bhatt S, Devadoss T, Mahesh R: Antidepressant and anxioltic-like effects of $4 \mathrm{n}$, a novel 5-HT3 receptor antagonist using behaviour based rodent models. Indian J Experimental Bio. 2012 50: 625-632.

13. Govindu S, Adikay S: Evaluation of antiepileptic activity of chloroform extract of Acalyphafruticosa in mice. Pharmacognosy Res. 2014 6(2): 108-112. http://dx.doi.org /10.4103/0974-8490.128970. 
14. Singh YN: Potential for interaction of kava and St. John's wort with drugs. J Ethno pharmacol. 2005 100: 108-113. http://dx .doi.org/10.1016/j.jep.2005.05.014

15. Paul BN, Saxena AK: Depletion of tumor necrosis factor-c-in mice by Nyctanthe sarbortristis. J Ethanopharmacol. 1997 56:153158.

16. Saxena RS, Gupta B, Lata S: Tranquilizing, antihistaminic and purgative activity of Nyctanthesarbortristis leaf extract. $J$ Ethnopharmacol. 2002 81(3):321-5.

17. Ratnasooriya WD, Jayakody JRAC, Hettiarachchi ADI, Dharmasiri MG: Sedative Effect of Hot Infusion of Nyctanthes arbortristis on Rats. Pharma Bio. 2005 43(2):140-146.

18. Aggarwa BB, Prasad S, Reuter S, Kannappan RS, Yadav VR, Park BD, et al: dentification of Novel Anti-inflammatory Agents from Ayurvedic Medicine for Prevention of Chronic Diseases: "Reverse Pharmacology" and "Bedside to Bench" Approach. Curr Drug Targets. 2011 12:1595-1653.

19. Akki KS, Krishnamurthy G, Bhojanaik HS: Phytochemical investigations and in vitro evaluation of Nyctanthes arbor-tristis leaf extracts for antioxidant property. J Pharm Res. 2009 2:752-759.

20. Tripathia S, Tripathia PK, Singh PN: Antidepressant activity of Nyctanthes arbortristis leaf extract. Pharmacology online 2010 3: 415422.

21. Basistha BC, Sharma NP, Lepcha L, Arrawatia A, Sen A: Ecology of Hippophae salicifolia D. Don of Temperate and Subalpine forests of North Sikkim Himalayas: A Case Study, Symbiosis 2010 50: 87-95.

22. Goyal AK, Basistha BC, Sen A, Middha SK: Antioxidant Profiling of Hippophae salicifolia Growing in Sacred Forests of Sikkim, India. Funct Plant Biol. 2011 38: 697701.

23. Upadhyay NK, Yogendra KMS and Gupta A: Antioxidant, Cytoprotective and Antibacterial Effects of Seabuckthorn (Hippophaerhamnoides L.) leaves", Food Chem Toxicol. 2011 48:3443-3448.

24. Gupta SK: Validation of claim of Tulsi, Ocimum sanctum Linn as a medicinal plant. J Expt Biol. 2002 40(7):765-77.

25. Javanmardi J, Stushnoff C, Lockeb E, Vivanco $\mathrm{JM}$ : Antioxidant activity and total phenolic content of Iranian Ocimum accessions. Food Chem. 2003 83: 547-550.

26. Misra L, Lal P, Sangwan RS, Sangwan NS, Uniyal GC, Tuli R: Unusuallysulfated and oxygenated steroids from Withania somnifera. Phytochem. 2005 66:2702-2707.

27. Mishra LC, Singh BB, Dagenais S: Scientific basis for the therapeutic use of Withaniasomnifera (ashwagandha): a review. Altern Med Rev. 2000 5: 334-346.
28. Guarrera S, Sacerdote C, Fiorini L, Marsala R, Polidoro S, Gamberini S, et al: Expression of DNA repair and metabolic genes in response to a flavonoid-rich diet. $B r \quad J$ Nutr. 2007 98(3):525-533.

29. Ekeanyanwu RC, Njoku OU: Acute and subacute oral toxicity study on the flavonoid rich fraction of Monodoratenuifoliaseed in albino rats. Asian Pac J Trop Biomed. 2014 4(3): 194- 202.

30. Dhir A, Naidu PS, Kulkarni SK: Protective effect of Cyclooxygenase- 2 (COX-2) inhibitors but not non-selective. Addict Biol. 2005 10: 329-335

31. Machado DG, Kaster MP, Binfaré RW, Dias M, Santos AR, Pizzolatti MG, et al: Antidepressant-like effect of the extract from leaves of Schimusmolle L. in mice; Evidence for the involvement of the monoaminergic system. Prog Neuropsycho pharmacol Biol Psychiatry. 2007 31: 421-428

32. Ekeanyanwu RC, Njoku OU: Flavonoid-rich fraction of the Monodora tenuifoliaseed extract attenuates behavioural alterations and oxidative damage in forced-swim stressed rats. Chin J Nat Medicines. 2015 13(3): 0183-0191

33. Porsolt RD, Lenegre A, McArthur RA: Pharmacological models of depression. In: Olivier B, Slangen J, Mos J (eds). Animal models in psychopharmacology, advances in pharmacological science. Birkhäuser: Basel 1991 137-5.

34. Millan MJ: The role of monoamines in the actions of established and "novel" antidepressant agents: a critical review. Eur J Pharmacol. 2004 1-3

35. Kulkarni SK, Reddy DS: Animal behavioural models for testing antianxiety activity. Methods Find ExpClin Pharmacol. 1996 18: $219-$ 230

36. Kulkarni SK. Handbook of Experimental Pharmacology. 3rd ed. Vallabh Prakashan, Delhi, 1999;117-118.

37. Snyder SH, Zweig M, Axelrod J: Control of circadian rhythm in the serotonin content of the rat pineal gland. Life Sci. 1964 3:1175-1179

38. Ozaki Y, Lynch HJ, Wurtman RJ: Melatonin in rat pineal, plasma and urine: 24-hour rhythmicity and effect of chlorpromazine. Endocrinology 1976, 98: 1418 -1424

39. Xu Y, Ku BS, Yao HY, Lin YH, Ma X, Zhang $\mathrm{YH}$, et al: Antidepressant effects of curcumin in the forced swim test and olfactory bulbectomy models of depression in rats. Pharmacol Biochem Behav. 2005 82:200-6.

40. Bohus B, Koolhaus JM, Heijnea CJ: Immunological responses to social stress; dependence on social environment and coping abilities. Neuropsychobiol. 1993 28:95.

41. Walesiuk A, Trofimiuk E, Braszko JJ: Ginkgo biloba normalises stress and corticosterone- 
induced impairment of recall in rats. Pharmacol Res 2006 53: 123.

42. Dalla C, Pitychoutis PM, Kokras N: Sex differences in response to stress and expression of depressive-like behaviours inthe rat. Curr Top Behav Neurosci 2011 8: 97118.

43. Tee TP, Hassan H: Antidepressant-like activity of Banana peelsextract in mice. Amer Med J. 2001 2(2): 59-64.

44. Nogueira E, Vassilieff VS: Hypnotic, anticonvulsant and muscle relaxant effects of Rubuslorasiliensis: involvement of GABAA system. J Ethnopharmacol. 2000 70: 275-280.

45. Nishikara H, Hata T, Funakami Y: A role for corticotropine- releasing factor in repeated cold stress-induced anxiety-like behaviour during forced swimming and elevated plusmaze test in mice. Biol Pharm Bulletin 2004 27: 252-256.

46. Brunello N, Mendlewicz J, Kasper S, Leonard B, Montgomery S, Nelson JC: The role of noradrenaline and selective noradrenaline reuptake inhibition in depression. Eur Neuro psycho pharmacol. 2002 12:461-75.

47. Liu J, Wang X, Mori A: Immobilisation stressinduced antioxidant defence changes in rat plasma; effect of treatment with reduced glutathione. Int J Biochem. 199426 : 511-517.;

48. Zafir A, Banu N: Antioxidant potential of Fluoxetine in comparison to curcuma longa in restraint stressed rats. Eur J Pharmacol. 2007 572(1): 23-31.

49. Goyal P, Anil K: Protective effect of alprazolam in acute immobilisation stress induced certain behavioural and biochemical alterations in mice. Pharmacol Rep. 2007 50: 284-290.

50. Umadevi P, Murugan S, JeniferSuganthi S: Evaluation of antidepressant like activity of Cucurbita pepo seed extracts in rats. Int J Curr Pharm Res. 2011 3(1): 108-113.

51. Kumar B, Kuhad A, Chopra K: Neuropsychopharmacological effect of sesamol in unpredictable chronic mild stress model of depression and biochemical evidences. Psycho pharmacol. 2011 214: 819-828.

52. Moretti M, Colla A, BalenGO: Ascorbic acid treatment, similarly to fluoxetine reverses depressive-like behaviour and brain oxidative damage induced by chronic unpredictable stress. J Psychiatric Res. 2012 46: 331-340.

53. Bach AW, Lan NC, Johnson DL, Abell CW, Bembenek ME, Kwan SW: cDNA cloning of human liver monoamine oxidase $A$ and B:molecular basis of differences in enzymatic properties. Proc Natl AcadSci. 1988 85:4934.

54. Iversen L: Neurotransmitter transporters and their impact on themdevelopment of psychopharmacology. Br J Pharmacol. 2006 147.
55. Millan MJ: The role of monoamines in the actions of established and "novel" antidepressant agents: a critical review. Eur J Pharmacol. 2004 1-3.

56. L'opez-Mũnoz F, Alamo C, Juckel G, and Assion HJ: Half a century of antidepressant drugs-on the clinical introduction of monoamine oxidase inhibitors, tricyclics, and tetracyclics part I: monoamine oxidase inhibitors. J Clin Psychopharmacol. 2007 555559. 